\title{
PROGRESS IN PESTICIDE RISK REDUCTION IN NEW ZEALAND HORTICULTURE
}

\author{
J.T.S. WALKER ${ }^{1}$, N.M. PARK ${ }^{1}$, B.E. CLOTHIER ${ }^{2}$, \\ D.W.L. MANKTELOW ${ }^{3}$, C.W. VAN DEN DIJSSEL ${ }^{2}$, A.J. HODSON ${ }^{4}$, \\ M.J. BARLEY ${ }^{4}$ and L.R. HODSON-KERSEY ${ }^{4}$ \\ ${ }^{I}$ The New Zealand Institute of Plant \& Food Research Limited, Private Bag \\ 1401, Havelock North, New Zealand \\ ${ }^{2}$ The New Zealand Institute of Plant \& Food Research Limited, Private Bag \\ 11030, Palmerston North, New Zealand \\ ${ }^{3}$ Manktelow \& Associates Ltd., PO Box 3415, Napier Mail Centre, RD2, Napier, \\ New Zealand \\ ${ }^{4}$ HortPlus, 1091 Riverslea Road South, RD2, Hastings, New Zealand \\ Corresponding author: jwalker@hortresearch.co.nz
}

\begin{abstract}
The New Zealand horticultural sector has made substantial progress in pesticide risk reduction by implementing sustainability programmes. Apple and winegrape pesticide use was analysed to measure changes in human and aquatic eco-toxicity arising from these initiatives using the Hazardous Substances and New Organism 1996 Act (HSNO) classification system. In 1995 insecticide use on apples and winegrapes was 11.6 and $0.31 \mathrm{~kg}$ ai $/$ ha respectively, while fungicide loadings were similar, about $30 \mathrm{~kg}$ ai/ha. Since then insecticide loading on apples has decreased by $80 \%$ with much lower potential human toxicity. Growers following Integrated Fruit Production guidelines reduced fungicide loadings by $45 \%$ but expansion of organic apple production increased the sector's total fungicide use. The wine sector has reduced their total agrichemical loading of insecticides by $72 \%$ and fungicides by $62 \%$, mostly through lower use of sulphur fungicides. Both sectors have reduced their use of agrichemicals that are potentially toxic to aquatic ecosystems. Keywords: pesticide risk, pesticide hazards, worker exposure, apples, winegrapes.
\end{abstract}

\section{INTRODUCTION}

The New Zealand apple industry comprises 520 growers who account for a total production area of 8945 ha. ENZA New Zealand International launched the Integrated Fruit Production (IFP) programme in 1996, which introduced major changes to pest and disease management in the pipfruit sector. This included a shift from calendar schedules of pesticide use to justified use, based on pest and disease monitoring systems and treatment thresholds. Specific programme goals were identified including the replacement of broadspectrum organophosphate (OP) insecticides with selective products compatible with biological control (Walker et al. 1997) and the elimination of residual herbicides for weed management. All New Zealand pipfruit is now grown under either IFP methods (91\% of planted hectares) or organic production systems (Pipfruit New Zealand Inc. 2006).

The New Zealand winegrape production area was 25,355 ha in 2007 and wine is exported to 85 countries. The Sustainable Winegrowing New Zealand (SWNZ) programme commenced in 1997 with implementation centred on a scorecard that includes many aspects of sustainability in winegrape production including soils and fertilisers, sward and irrigation management, diseases and pest management (Gurnsey et al. 2004). Pest and disease control within SWNZ also gives priority to biological and cultural control 
practices, with pesticides applied only when necessary. Selective pesticides compatible with biological control are used where possible (Lo \& Walker 2006).

Sustainability programmes in both apple and winegrape sectors were introduced in recognition of the increasing focus in export markets on food safety and environmental issues affecting horticultural production systems. Both sectors focussed on changing crop protection strategies as a key performance measure of their programmes' success. This resulted in both reductions in pesticide use and changes to the toxicity profiles of the pesticides used.

The Hazardous Substance and New Organisms (HSNO) Act was introduced in 1996 to provide an integrated and consistent approach for the management of hazardous substances and new organisms in New Zealand. The controls set out in HSNO regulations are based on a classification scheme that is defined as a combination of the hazardous property of a substance and the level or type of hazard related to that property. Each hazardous substance is assessed and assigned a classification that reflects the type and degree of its hazard, with higher hazards subjected to stricter controls (ERMA New Zealand 2006). Pesticides classed as hazardous substances are most likely to trigger thresholds for the hazardous properties described in Class 6.1 (acute human toxicity) and Classes 9.1 and 9.2 (aquatic and soil toxicity). These classes contain some of the key pesticides that have been targets for reduction or elimination in the apple and wine sector sustainability programmes.

This paper uses the HSNO classification system to examine changes in human and environmental hazard profiles associated with changing pesticide use in these sectors' sustainability programmes, IFP and SWNZ. Both programmes acted as drivers for change in growers' crop protection practices and affected product use and development throughout the wider agrichemical sector. The impact of the crop protection changes on both the human and aquatic eco-toxicity profiles associated with pesticide use in these sectors are examined.

\section{METHODS}

Pesticide use information from apple and winegrape growers' spray diaries were assessed across timeframes that covered the implementation of their respective sustainability programmes. For IFP, this analysis was based on 14,080 apple block spray diaries from 1720 orchards in 1995 just prior to the introduction of IFP. These data were compared with 7352 block spray diaries from 892 orchards in 2008. Similar information from the wine sector was more limited with 104 winegrape block spray diaries from 58 vineyards in 1999 and 2271 winegrape block spray diaries from 322 vineyards in 2007.

Toxicity profiles for each sector were developed from the HSNO classifications for human toxicity and aquatic eco-toxicity (ERMA New Zealand 2008). For acute human toxicity, class 6.1 defines the potential risks for human exposure ranging from those most acutely hazardous in $6.1 \mathrm{~A}$ (oral $\mathrm{LD}_{50}$ of $\leq 5 \mathrm{mg} / \mathrm{kg}$ bodyweight (bw) and a dermal $\mathrm{LD}_{50}$ of $\leq 50 \mathrm{mg} / \mathrm{kg} \mathrm{bw}$ ) through to $6.1 \mathrm{E}$ (oral $\mathrm{LD}_{50}$ of $\leq 5000 \mathrm{mg} / \mathrm{kg}$ bw and a dermal $\mathrm{LD}_{50}$ of $\leq 5000 \mathrm{mg} / \mathrm{kg} \mathrm{bw})$. Class 9.1 defines the potential risks of exposure to waterways, and the most toxic Class 9.1A agrichemicals are defined as those with an acute toxicity of $\leq 1 \mathrm{mg} /$ litre of water.

The HSNO classifications were available for a high proportion of the 1995 and 1999 datasets, as most products available in 1995 and 1999 have been transferred to the HSNO classification system. Those that were not available were estimated from similar products and formulations that were transferred. A small number of products were not included in the risk profiles because it was not possible to estimate their HSNO classification. Active ingredient use per hectare was determined from the spray diary datasets (calculated from the product active ingredient content, the product and water rates per ha). Mineral oils are applied to apples at rates of 20 litres/ha for control of scale insects and mites; their use has not changed since 1995 . They have a low HSNO human toxicity classification (6.1E) and were omitted from this study because a single, high rate application would mask all other trends in insecticide use. 


\section{Apples}

\section{RESULTS AND DISCUSSION}

Changes in the HSNO classification profiles for both potential human and environmental exposure for insecticide and fungicide use in the apple sector are given in Figures 1 \& 2 respectively. The comparison is between current use (2008) and 1995, prior to the sectors' introduction of the IFP programme.

Since 1995 there has been an $80 \%$ reduction in the quantity of Class 6.1 insecticides used in the apple sector, with average active ingredient use declining from 11.6 to just $2.3 \mathrm{~kg}$ ai/ha in 2008. In addition to this reduction in total use, there have been significant shifts in the hazard profile of the insecticides used. Average use of Class 6.1A and 6.1B insecticides (mostly azinphos-methyl formulations) was $4 \mathrm{~kg} / \mathrm{ha}$ in 1995 (Fig. 1), whereas in 2008 these acutely toxic insecticides were not used.

Although less acutely toxic, there has been a significant decrease in the use of Class 6.1C insecticides (principally chlorpyrifos, carbaryl and diazinon), with their use declining from $5 \mathrm{~kg} / \mathrm{ha}$ in 1995 to just $1.6 \mathrm{~kg} / \mathrm{ha}$ in 2008 . Carbaryl use, principally for fruit thinning rather than pest management, accounts for most of the remaining Class 6.1C insecticide use in 2008. Some of the primary insecticides now used in apple pest management (e.g. methoxyfenozide, tebufenozide, spinetoram and spinosad) are of such low acute human toxicity that they do not register within the Class 6.1 hazard classification scheme. Nearly all insecticide use in 1995 was in Class 9.1A, or highly toxic to aquatic ecosystems. While this is also true for insecticides used in 2008, the loading has decreased by $80 \%$ from 11.6 to $2.3 \mathrm{~kg} / \mathrm{ha}$, as many of the new insecticides are used less frequently under IFP pest management guidelines and are effective at much lower rates.

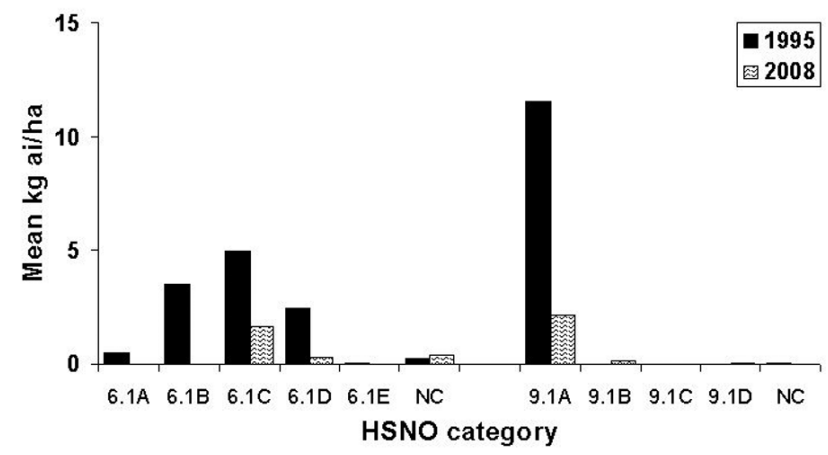

FIGURE 1: The mean quantity of active ingredient in $\mathrm{kg}$ ai/ha of HSNO classified 6.1 (human toxicity) and 9.1 (eco-toxic) insecticides applied to apple crops in 1995 and 2008 . NC includes pesticides that are not classified because they are not considered to be toxic under the HSNO classification scheme.

Since 1995 there has been a small apparent increase in fungicide use from 30.8 to $33.5 \mathrm{~kg}$ ai/ha. Use of fungicides on IFP orchards has decreased significantly, but it is the sector's use of lime sulphur $(13.9 \mathrm{~kg}$ ai/ha) that accounts for this increase. This is largely attributable to its use on organic apple crops (7\% of total apple production) at rates of 5-10 litres/ha throughout spring. There were no acutely hazardous Class $6.1 \mathrm{~A}$ and 6.1B fungicides applied to IFP apple crops in 1995. The increase in Class 6.1B in 2008 is attributable to use of tolyfluanid, principally for the control of apple black spot and European canker. Average use of Class 6.1C fungicides (dominated by the protectant fungicides captan and dodine) has also declined by $72 \%$ to just $1.7 \mathrm{~kg}$ ai/ha in 2008 , as 
growers have sought to further reduce or even eliminate the residues of these products, indeed all pesticide residues, on export apple crops. Class 9.1A fungicides dominated apple disease management programmes in 1995. Use of these compounds, with high potential toxicity to aquatic ecosystems, has decreased by $43 \%$ from 30.1 to $17.2 \mathrm{~kg} / \mathrm{ha}$ in 2008.

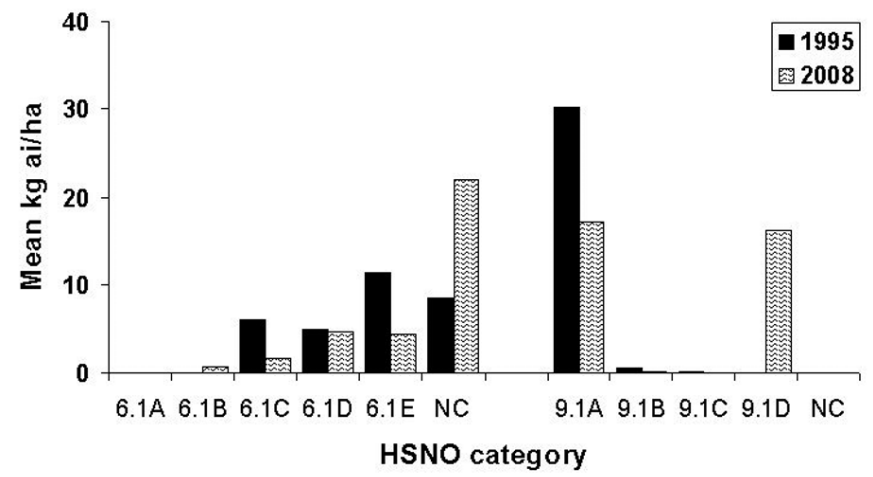

FIGURE 2: The mean quantity of active ingredient in $\mathrm{kg}$ ai/ha of HSNO classified 6.1 (human toxicity) and 9.1 (eco-toxic) fungicides applied to apple crops in 1995 and 2008. NC includes pesticides that are not classified because they are not considered to be toxic under the HSNO classification scheme.

These shifts in toxicity profiles, especially insecticides, have been an important advance for growers who are significantly more exposed than any other group to the potential risk of acute pesticide toxicity. These risks occur through the quantity of, and frequency of, their exposure to pesticides during mixing and application and when re-entry into treated areas is required for orchard management. The change in insecticide use since 1995 has resulted in the average number of Class 6.1A, B and C insecticide sprays applied by growers declining from 7.3 to 0.85 per season, an $88 \%$ reduction. This is a significant reduction in the number of potential exposure events for growers mixing and applying crop protection products to apples. This is fortuitous as consolidation in the sector has introduced opposing trends that potentially increase the risk of human exposure including increases in block sizes and the number of mixing events per grower and a significant shift from dilute applications ( 2000 litres/ha) towards 3-5 times concentrate applications (700-500 litres/ha).

\section{Winegrapes}

Changes in the HSNO classification profiles for both potential human and environmental exposure to pesticides are given for insecticides and fungicides in Figures $3 \& 4$ respectively. The comparison is between use in 2007 and 1999, prior to widespread adoption of the SWNZ programme.

Since 1999 there has been a $72 \%$ reduction in the quantity of Class 6.1 insecticides used in the winegrape sector, with average active ingredient use declining from what was already a low level of 0.3 to just $0.1 \mathrm{~kg}$ ai/ha in 2007 . In addition to this, there has been a shift in the hazard profile of the insecticides used. The acutely toxic Class 6.1A and 6.1B insecticides were not used on winegrapes in either 1999 or 2007. There has been a decline in the use of $6.1 \mathrm{C}$ insecticides (principally chlorpyrifos for mealybug control) from 0.1 to $0.001 \mathrm{~kg}$ ai/ha. Carbaryl and methomyl (for mealybug control) and lambda-cyhalothrin (for beetle control) account for most of the remaining Class 6.1C insecticide use in 2007. Some of the primary insecticides now used in winegrape pest 
management (e.g. methoxyfenozide, tebufenozide, spinosad and some formulations of buprofezin) are of such low acute human toxicity that they do not register within the Class 6.1 hazard classification scheme. Other insecticides used register a low toxicity classification including prothiofos (Class 6.1D) and some buprofezin formulations (Class $6.1 \mathrm{E}$ ), both used for mealybug control. Although insecticide use in winegrape production is relatively low, use of insecticides that are highly toxic to aquatic ecosystems (Class 9.1A) has declined by $70 \%$ since 1999 .

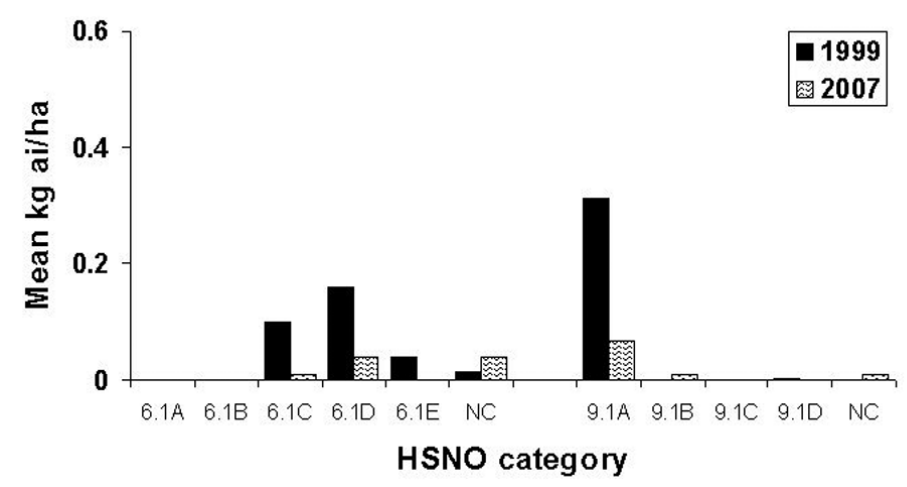

FIGURE 3: The mean quantity of active ingredient in $\mathrm{kg}$ ai/ha of HSNO classified 6.1 (human toxicity) and 9.1 (eco-toxic) insecticides applied to winegrapes in 1999 and 2007. NC includes pesticides that are not classified because they are not considered to be toxic under the HSNO classification scheme.

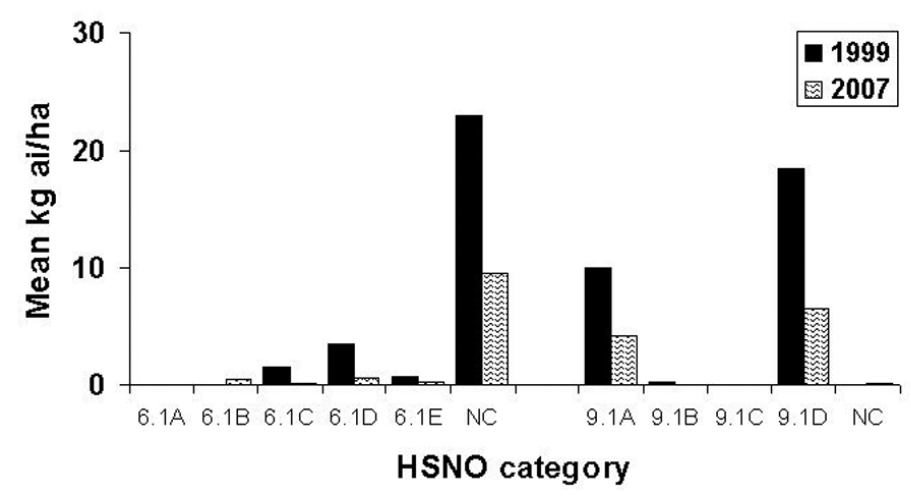

FIGURE 4: The mean quantity of active ingredient in $\mathrm{kg}$ ai/ha of HSNO classified 6.1 (human toxicity) and 9.1 (eco-toxic) fungicides applied to winegrapes in 1999 and 2007. NC includes pesticides that are not classified because they are not considered to be toxic under the HSNO classification scheme. 
Since 1999 there has been a $62 \%$ reduction in fungicide use from 28.8 to $11.0 \mathrm{~kg}$ ai $/ \mathrm{ha}$. This significant reduction has largely been attributable to a reduction in the use of sulphur (no class 6.1 classification) and copper (Class 6.1D classification). There were no acutely hazardous Class 6.1A and 6.1B fungicides applied in 1999. The increase in Class 6.1B in 2007 is attributable to the use of tolyfluanid and chlorothalonil for downy mildew, powdery mildew and botrytis control. Average use of Class 6.1C fungicides has significantly declined to $0.2 \mathrm{~kg}$ ai/ha in 2007 (predominantly some captan formulations). Use of ecotoxic Class 9.1A fungicides has also decreased by $58 \%$ since 1999. Further decreases in both potential human and ecotoxicity are likely to occur through SWNZ initiatives that look to reduce or eliminate all pesticide residues on winegrapes.

\section{CONCLUSIONS}

The HSNO classification system has provided an important insight into the impact of sustainability initiatives on pesticide use and selection in the apple and winegrape sectors. For the first time, significant shifts in both pesticide acute toxicity to humans and environmental toxicity have been assessed in these two sectors using consistent hazard assessment criteria. The sectors had very different crop protection profiles for pest management at the outset of their sustainability programmes; in 1995 the insecticide loading in apples was $11.6 \mathrm{~kg}$ ai/ha, while use in winegrapes was just $0.31 \mathrm{~kg}$ ai $/ \mathrm{ha}$. In the apple sector's IFP programme the emphasis on OP insecticide elimination, together with the introduction of pest monitoring, threshold-based treatments and selective pest management have allowed significant decreases in both the pesticide loading and the substantial shift in acute human and environmental toxicity profiles. Wet weather diseases, especially apple blackspot and botrytis in grapes, drive fungicide use in both crops so at the outset of these programmes fungicide loadings were similar; $30.8 \mathrm{~kg}$ ai/ha in apples and $28.8 \mathrm{~kg}$ ai/ha in winegrapes. The expansion of organic apple production and the consequential increase in lime sulphur use has largely overshadowed the progress achieved in the IFP programme where the fungicide loading has declined by $45 \%$ to $16.9 \mathrm{~kg}$ ai/ha. The wine sector has achieved a significant reduction in total fungicide loading, with the largest decrease occurring for sulphur fungicides, where use has declined by $5.8 \mathrm{~kg}$ ai/ha. Through their sustainability programmes, both sectors have significantly reduced their use of products that are potentially acutely toxic in aquatic ecosystems (Class 9.1).

This analysis has highlighted some other significant changes that have been introduced by the agrichemical sector to reduce the potential acute human toxicity of pesticides. This includes the impact of formulation changes on toxicity of some of the commonly used pesticides. For example, different formulations of captan can be found in HSNO 6.1C and D classifications while others are unclassified (i.e. not acutely human toxic). Other examples include various formulations of chlorpyrifos, dodine and diazinon. The progress achieved with sustainability initiatives in apples and winegrapes has only been possible through the responsiveness of the agrichemical sector to the sustainability programmes.

The HSNO classification system has provided an important framework for objective assessment of the impact of the apple and winegrape sectors' sustainability initiatives. It can therefore assist these sectors, and others using agrichemicals, to chart their future pesticide risk reduction goals while also providing a framework for measuring their progress. At an individual level, the HSNO classification system provides a framework to guide growers in their selection of pesticides, albeit somewhat complex for any potential user to interpret across the many categories of hazard and potential risk. The recent development of a decision-support system, 'Spray Plan Manager' (Walker et al. 2007), greatly simplifies this interpretation for growers by providing comparative information on the wide selection of active ingredients and product formulations that can be used as part of an effective crop protection programme. This concept allows pesticide users to develop, implement and measure their progress towards agrichemical risk reduction without the compulsion of a national pesticide risk reduction policy. 


\section{ACKNOWLEDGEMENTS}

This work was funded by the New Zealand Foundation for Research, Science and Technology (Contract C02X0303). We would like to thank Dr Mike Butcher (Pipfruit NZ Ltd) and Mr Philip Manson (New Zealand Winegrowers Ltd) for their valued comments on this manuscript and for access to spray diary information.

\section{REFERENCES}

ERMA New Zealand 2006. A guide to the hazardous substances and new organisms act. Environmental Risk Management Authority, Wellington, New Zealand. 53 p. Available at www.ermanz.govt.nz (accessed 15 April 2009).

ERMA New Zealand 2008. User guide to the thresholds and classifications under the Hazardous Substances and New Organisms Act 1996, v2.0. March 2008. Environmental Risk Management Authority, Wellington, New Zealand. Available at www.ermanz.govt.nz (accessed 15 April 2009).

Gurnsey S, Manktelow DWL, Manson P, Walker JTS, Clothier BE 2005. Sustainable Winegrowing New Zealand: Technical developments and achievements. In: Cross J, Ioriatti C ed. Proceedings of the 6th International Conference on Integrated Fruit Production. Baselga di Piné, Italy, 26-30 September 2004. IOBC-WPRS Bulletin 28(7): 444 (Abstract only).

Lo PL, Walker JTS 2006. Monitoring leafrollers (Lepidoptera:Tortricidae) in vineyards. New Zealand Plant Protection 59: 317-322.

Pipfruit New Zealand Inc. 2006. Pipfruit industry statistical annual 2006. Pipfruit New Zealand Inc, Hastings, New Zealand. 40 p.

Walker JTS, Hodson AJ, Wearing CH, Bradley SJ, Shaw PW, Tomkins AR, Burnip GM, Stiefel HE, Batchelor TA 1997. Integrated fruit production for New Zealand: Evaluation of pest management in a pilot programme. Proceedings of the 50th New Zealand Plant Protection Conference: 258-263.

Walker JTS, Park NM, Hodson AJ, Barley MJ, Hodson-Kersey LR, Clothier BE, van den Dijssel CW, Manktelow DWL 2007. Agrichemical application issues for growers, communities and the environment. In: Butcher MR, Walker JTS, Zydeenbos SM ed. Future Challenges in Crop Protection: Repositioning New Zealand's Primary Industries for the Future. New Zealand Plant Protection Society, Hastings, New Zealand. Pp. 87-97. 